\title{
Does physical training increase insulin sensitivity in chronic heart failure patients?
}

\author{
L. W. E. SABELIS*, P. J. SENDEN†, B. C. M. TE BOEKHORST*, H. J. HULZEBOS‡, \\ A. VAN DE WIEL $\S$, T. W. VAN HAEFTEN $\|$, M. L. ZONDERLAND* and W. L. MOSTERD*† \\ *Department of Sports Medicine, University Medical Centre, Utrecht, The Netherlands, †Department of Cardiology, \\ Meander Medical Centre, Amersfoort, The Netherlands, $\ddagger$ Department of Rehabilitation, University Medical Centre, Utrecht, \\ The Netherlands, §Internal Medicine, Meander Medical Centre, Amersfoort, The Netherlands, and \|Department of Internal \\ Medicine, University Medical Centre, Utrecht, The Netherlands
}

\section{A}

To determine the effect of training on insulin sensitivity (IS) and how this relates to peak $\dot{\mathrm{V}}_{2}$ (peak oxygen uptake) in CHF (chronic heart failure), $77 \mathrm{CHF}$ patients (New York Heart Association class, II/III; men/women, 59/I8; age, $60 \pm 9$ years; body mass index, $26.7 \pm 3.9 \mathrm{~kg} / \mathrm{m}^{2}$; left ventricular ejection fraction, $26.9 \pm 8.1 \%$; expressed as means \pm S.D.) participated in the study. Patients were randomly assigned to a training or control group ( $\operatorname{TrG}$ or CG respectively). Sixty-one patients completed the study. Patients participated in training (combined strength and endurance exercises) four times per week, two times supervised and two times at home. Before and after intervention, anthropometry, IS (euglycaemic hyperinsulinaemic clamp) and peak $\dot{V}_{2}$ (incremental cycle ergometry) were assessed. Intervention did not affect IS significantly, even though IS increased by $20 \%$ in $\operatorname{TrG}$ and II \% in CG (not significant). Peak $\dot{V}_{\mathrm{O}_{2}}$ increased as a result of training ( $6 \%$ increase in TrG; $2 \%$ decrease in CG; $P<0.05$ ). In both groups ( $\operatorname{TrG}$ and $C G$ ), the change in IS correlated positively with the change in peak $\dot{V}_{2}(r=0.30, P<0.05)$. Training resulted in an increase in peak $\dot{V}_{2}$, but not in IS. Whether physical training actually increases IS in CHF patients remains unclear.

\section{INTRODUCTION}

Chronic heart failure (CHF) is characterized by a compromised LVEF (left ventricular ejection fraction) and changes in peripheral tissues. These include abnormalities in mitochondrial structure and function, alterations in the oxidative metabolism of skeletal muscle and atrophy of predominantly oxidative insulin-sensitive type I fibres in skeletal muscle, resulting in a relatively larger proportion of glycolytic, less insulin-sensitive type IIb fibres, and impaired peripheral blood flow. These peripheral changes are associated with decreased exercise tolerance [1]. Compared with healthy subjects, insulin sensitivity (IS) has been shown to be impaired in CHF $[2,3]$. Usually, insulin induces vasodilatation; this effect has been shown to be impaired across a number of insulin-resistant states [4]. This might explain the impaired peripheral blood flow and, consequently, the decreased exercise tolerance in CHF. However, studies are inconclusive regarding the relationship between IS and peak $\dot{V}_{\mathrm{O}_{2}}$ (peak oxygen uptake) in CHF, since a positive relationship has been reported in several [5,6], but not all [7] studies. In healthy subjects and diabetic patients, this relationship is common [8].

During the last decade, investigations have established that physical training has beneficial effects on, among other things, exercise tolerance $[9,10]$ in compensated $\mathrm{CHF}$. The increase in exercise tolerance has been

Key words: chronic heart failure, euglycaemic clamp, insulin sensitivity, physical training, randomized controlled trial.

Abbreviations: ACE, angiotensin-converting enzyme; BMI, body mass index; CG, control group; CHF, chronic heart failure; DPA, daily physical activity; FFM, fat-free mass; FM, fat mass; HR, heart rate; HOMA, homoeostasis model assessment; IFG, impaired fasting glucose; IS, insulin sensitivity; LVEF, left ventricular ejection fraction; peak $\dot{V}_{2}$, peak oxygen uptake; $\operatorname{TrG}$, training group; WC, waist circumference.

Correspondence: Dr Louise W. E. Sabelis (L.W.E.Sabelis@med.uu.nl). 


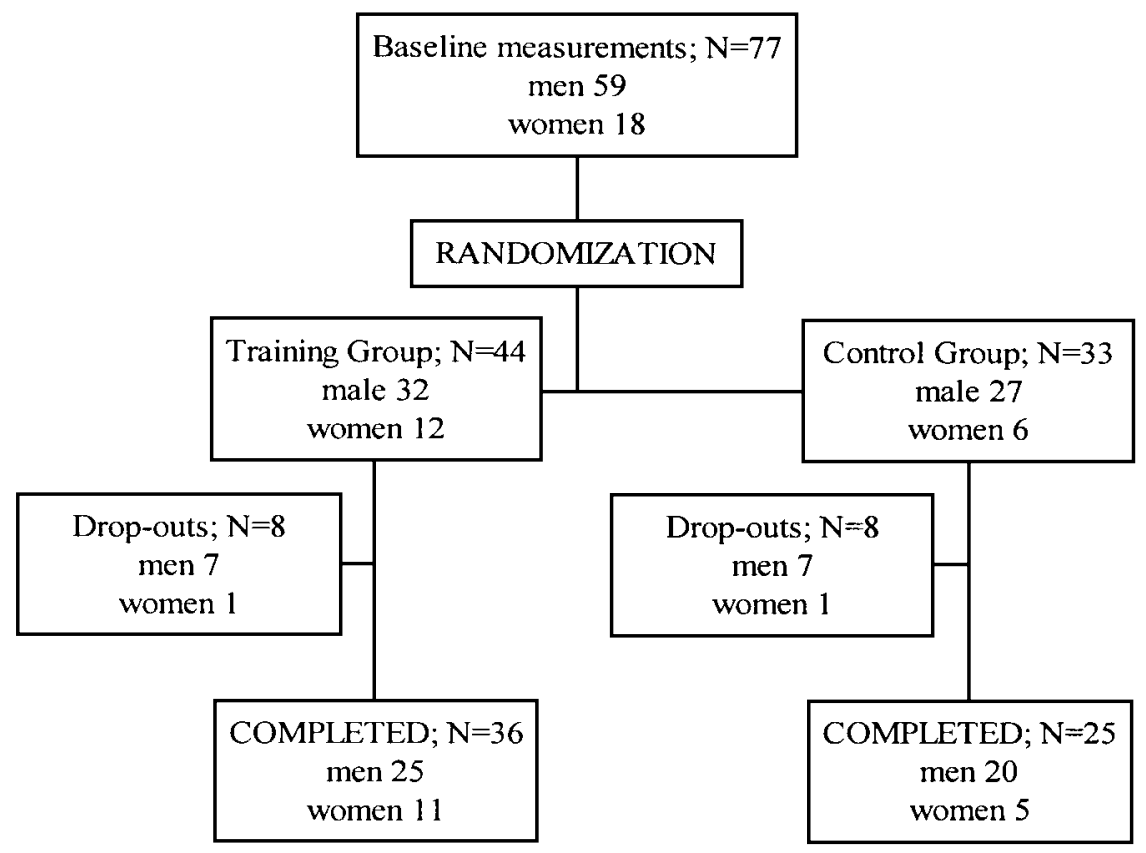

Figure I Flowchart of patient inclusion

attributed to an improved vasoregulation [11], which might be a consequence of an improvement in IS. In healthy subjects and diabetic patients, physical training usually results in an increase in peak $\dot{V}_{2}$ concomitantly with an increase in IS [8]. To date, in CHF patients, the effect of physical training on IS has been subject of two studies [3,5]. In the study of Kemppainen et al. [3], an increase in IS concomitantly with an increase in peak $\dot{V} \mathrm{O}_{2}$ was found; however, the study was not randomized and very small. In the study of Pietilä et al. [5], a larger group of patients participated, and peak $\dot{V}_{\mathrm{O}_{2}}$ and IS were increased only in combination with the use of the selective $\beta$-blocker Celiprolol. Unfortunately, in that study a nontraining control group was lacking. Therefore data about the relationship between IS and peak $\dot{V}_{\mathrm{O}_{2}}$, and the effect of training on both parameters, are scarce and speculative. Therefore the aim of the present study was to systematically investigate the effect of a 6-month training program on IS using a randomized controlled design, and to describe how this relates to exercise tolerance, represented by peak $\dot{V}_{\mathrm{O}_{2}}$, in CHF patients.

\section{METHODS}

\section{Study population and protocol}

The present study is part of the study project 'Training, insulin sensitivity and anabolic/catabolic balance in chronic heart failure'. Patients were recruited from three community hospitals in the Utrecht region. Inclusion criteria were a history of CHF longer than 6 months classified as New York Heart Association class II/III, with a LVEF of less than $35 \%$. Exclusion criteria were as follows: interfering diseases, such as chronic obstructive pulmonary disease, fasting glucose level of more than $7.0 \mathrm{mmol} / \mathrm{l}$ (i.e. diabetes mellitus), neuromuscular disorders and hypertension (systolic blood pressure higher than $170 \mathrm{mmHg}$ and/or diastolic blood pressure higher than $110 \mathrm{mmHg}$ when on optimal antihypertensive therapy). All patients had to be clinically stable for at least 4 weeks before randomization. The following criteria were used to asses the presence of ischaemic heart disease as the cause of CHF: a documented history or admission for acute coronary syndrome, electrocardiographic evidence of myocardial infarction, a positive exercise test, echocardiographic evidence of segmental wall motion abnormalities, significant coronary artery lesions on angiography, myocardial infarction or ischaemia demonstrated by nuclear imaging. If none of these conditions were met, the patients were considered to have non-ischaemic cardiomyopathy. Impaired fasting glucose (IFG) was said to be present when the fasting glucose concentration was between 6.1 and $7.0 \mathrm{mmol} / \mathrm{l}$ [12]. A flowchart of patient inclusion in the study is shown in Figure 1. Seventy-seven patients (male/female, 59/18; aged 40-70 years) entered this study. Sixty-one patients used ACE (angiotensin-converting enzyme) inhibitors, eight patients angiotension type II receptor blockers, 37 patients $\beta$-blockers and 44 patients loop diuretics. Medication use did not differ from the common daily routine in Europe [13]. During the study, patients continued to use their medication.

Patients were stratified according to gender, age (over or under 60 years) and peak $\dot{V}_{\mathrm{O}_{2}}$ (female: over or under 
$17.5 \mathrm{ml} / \mathrm{kg}$ per min; male: over or under $20.0 \mathrm{ml} / \mathrm{kg}$ per $\mathrm{min}$ ), and randomly assigned to the control group (CG) or training group ( $\operatorname{TrG}$ ). Ten patients from the CG reentered the study in order to participate in the $\operatorname{TrG}$. This group of patients was measured before and after each intervention period.

During intervention, which lasted 26 weeks, the $\operatorname{TrG}$ took part in a training program, while the CG received usual care. In addition, patients in the CG were contacted at least two times for evaluation of their well-being. Before and immediately after intervention, all patients underwent measurements of LVEF, body composition, IS, DPA (daily physical activity), and peak $\dot{V} \mathrm{O}_{2}$.

\section{Training program}

The training program lasted 26 weeks, with exercise at a frequency of at least four times per week. The program was supervized in an outpatient clinic two times per week and patients exercised at least two times per week at home.

The home training program was an adaptation of the ‘5BX plan for physical fitness in men' [14]. In short, the program comprised three charts of exercises, in progressive order of difficulty. Each chart consisted of five exercises to be performed in the same order. Exercise 1 was an exercise for relaxation and flexibility of the large muscle groups; exercise 2, 3 and 4 were strength exercises for the abdominal muscles, gluteal muscles, and the posterior leg musculature and arm muscles respectively; exercise 5 was an endurance exercise. All exercises could be performed at various levels. Home training lasted $11 \mathrm{~min}$ for each session. Work load was adapted as physical fitness changed. Patients advanced to the next level only when they could perform the exercises comfortably within the time limit.

Training sessions in the outpatient clinic were supervised by a physiotherapist and lasted approx. $1 \mathrm{~h}$. Training started with a warm-up session, followed by interval training, designed for $\mathrm{CHF}$ patients, on a cycle ergometer. Work phases of $30 \mathrm{~s}$ were alternated with recovery phases of $60 \mathrm{~s}$; this cycle was repeated ten times. Intensity of training was set at $50 \%$ of the maximum short-term exercise capacity, determined by a steep ramp test [15]. Every 4 weeks the steep ramp test was repeated to adapt workload for the following 4-week period. The other part of the supervised training session was an adjusted version of the home training program. Instead of performing the five exercises consecutively, exercises were separated by a recovery period of $30 \mathrm{~s}$ and lasted $1 \mathrm{~min}$ each for exercises $1-4$ and $6 \mathrm{~min}$ for endurance exercise 5. Training sessions were ended with a cooldown. Intensity of training during the adjusted version of the home training program was regularly monitored by measuring the heart rate (HR) during training sessions. Target HR was over $70 \%$ of peak HR measured during the steep ramp test.
Compliance to the training program was computed from diaries of the patients and from records kept by the physiotherapist. $100 \%$ compliance for the home training program was set at two training sessions per week. Compliance exceeded $100 \%$ for patients exercising more frequently at home.

\section{LVEF}

LVEF was determined by ultrasound (Hewlett-Packard, Andover, MA, U.S.A.) in the left recumbent position as close as possible to end expiration. LVEF was calculated online, according to the biplane disc summation method (Simpson's formula) [16].

\section{Body composition}

Percentage body fat was estimated from skin-fold thickness [17]. FM (fat mass) and FFM (fat-free mass) were calculated from the percentage body fat and total body weight. BMI (body mass index) was calculated as weight per height squared $\left(\mathrm{kg} / \mathrm{m}^{2}\right)$. To assess body fat distribution, waist circumference (WC) was measured at the level of the umbilicus.

\section{IS}

IS was assessed using an euglycaemic hyperinsulinaemic clamp (insulin infusion $3 \mathrm{~m}$-units/kg per $\mathrm{min}$ for $180 \mathrm{~min}$ ) [18]. This method is regarded as the 'gold standard' for measuring IS. Haematocrit was assessed every $1 \mathrm{~h}$ in order to convert blood glucose value into plasma glucose concentration. Glucose was measured at bedside with a glucose analyser (2300 Stat, YSI, Yellow Springs, OH, U.S.A.), insulin was measured by chemiluminescense immunoassay (Immulite 1 analyser, DPC, Los Angeles, CA, U.S.A.), with intra- and inter-assay coefficients of variation of $7.6 \%$ and $10.0 \%$ respectively.

IS was defined as the ratio of the average glucose infusion rate per $\mathrm{kg}$ of FFM and the average plasma insulin level during the 3 rd hour of the clamp.

The HOMA (homoeostasis model assessment) index was calculated using the following formula

$$
\begin{aligned}
\text { HOMA }= & (\text { fasting plasma glucose } \\
& \times \text { fasting plasma insulin }) / 22.5
\end{aligned}
$$

and was used as an index of IS. An index higher than 1.1 suggests impaired IS [19].

\section{Exercise tolerance}

\section{Physical activity questionnaire}

The modified Baecke questionnaire for physical activity in elderly people was used for assessment of DPA. This questionnaire has been validated for the Dutch elderly population [20]. The questionnaire consisted of scores for 'household activities', 'sports activities' (excluding the training program) and 'other leisure time activities', 
resulting in the DPA score. All activities were classified according to work posture and movements. An intensity code was used to classify each type of activity. The higher the activity score the more active the patient. The questionnaire took about $15 \mathrm{~min}$ to complete.

Peak $\dot{V}_{2}$

Exercise tolerance was determined by means of incremental cycle ergometry (Excalibur, Lode, Groningen, The Netherlands) with increments of $20 \mathrm{~W}$ every $3 \mathrm{~min}$ preceded by a warm-up period of $30 \mathrm{~s}$ unloaded cycling. The test was ended when the patient was restricted by symptoms or could not maintain the pedal frequency of at least $65 \mathrm{rev} . / \mathrm{min}$. Verbal encouragement was used to stimulate the patient to persevere till maximal exhaustion. HR was calculated from continuous ECG recordings. Blood pressure was measured during the final $30 \mathrm{~s}$ of each workload. Ventilatory parameters were registered breathby-breath (Oxycon $\beta$, Mijnhart-Jaeger, Bunnik, The Netherlands). The Oxycon $\beta$ was calibrated before each test. Data were recorded at $15 \mathrm{~s}$ intervals and respiratory exchange ratios and ventilatory equivalents for $\mathrm{O}_{2}$ and $\mathrm{CO}_{2}$ were calculated. Peak workload was defined as the sum of the last completed 3-min workload plus the time-corrected contribution of the final uncompleted workload. Oxygen uptake at peak exercise (peak $\dot{V}_{\mathrm{O}_{2}}$ ) was calculated as the mean of the values during the final $30 \mathrm{~s}$ of exercise.

\section{Statistical analysis}

Statistical analysis was performed with SPSS (Windows version 10.0). The sample size was calculated as follows: the number of subjects was chosen to ensure enough degrees of freedom for multivariate statistical analysis, with a power of at least 0.80 to detect within and between differences on the primary and secondary dependents.

Log-transformed values were used for IS, fasting insulin level and BMI. Simple bivariate relationships were calculated using Pearson's correlation coefficient. To test for differences in (distribution of) relevant variables, oneway ANOVA and $\chi^{2}$ test were used. Effect of intervention was assessed using repeated measures ANOVA.

For ordinal variables, differences between groups were assessed using the Mann-Whitney $U$ test, changes within groups were analysed using the Wilcoxon signed-ranks test.

A probability value of $P \leqslant 0.05$ was considered significant. All results are expressed as means \pm S.D.

\section{Ethical standards}

This study was been carried out in accordance with the Declaration of Helsinki (2000) of the World Medical Association, and has been approved by the Medical Ethics Committees of the hospitals where patients were recruited. All patients gave their written informed consent.
Table I Demographics of TrG and CG

\begin{tabular}{|c|c|c|c|}
\hline & TrG & CG & $P$-value $\dagger$ \\
\hline Number of patients & 36 & 25 & \\
\hline Male/female & $25 / I I$ & $20 / 5$ & ns \\
\hline \multicolumn{4}{|l|}{ Aetiology of heart failure } \\
\hline (Non)ischaemic & (I7) 19 & (12) 13 & ns \\
\hline Number of smokers & 3 & 9 & ns \\
\hline \multicolumn{4}{|l|}{ Race } \\
\hline Caucasian & 35 & 24 & ns \\
\hline Asian & I & I & ns \\
\hline \multicolumn{4}{|l|}{ Medication use* } \\
\hline ACE inhibitors & 27 & 21 & ns \\
\hline Loop diuretics & 19 & 15 & ns \\
\hline Non-selective $\beta$-blocker & 6 & 6 & ns \\
\hline Selective $\beta$-blocker & 12 & 7 & ns \\
\hline \multicolumn{4}{|c|}{$\begin{array}{l}* \text { Patients used a combination of these various kinds of medication. } \\
\chi^{\dagger} \text { Difference between training and control groups. ns, not significant. } P>0.05 \text {, }\end{array}$} \\
\hline
\end{tabular}

\section{RESULTS}

\section{Study population}

Sixteen patients ( $21 \%$ ), eight from the $\operatorname{TrG}$ and eight from the CG, dropped out during intervention for the following reasons: six died (not related to intervention), seven stopped for personal reasons and three could not be reassessed for medical reasons (cardiac decompensation, aneurysm of the aorta and muscle injury in the leg) not related to intervention. Consequently, 61 patients ( $36 \operatorname{TrG}$ and 25 CG) completed the study (Figure 1).

There were no differences between the drop-out patients and those who completed the study with respect to age, anthropometry, LVEF, exercise tolerance, glucose metabolism, DPA score, medication use, aetiology of heart failure or composition of the groups (male or female; CG or $\operatorname{TrG}$ ). At baseline, IFG was present in three patients in $\operatorname{TrG}$ and in six patients in CG, this was not significantly different.

In the ten patients that first participated in CG and thereafter in $\operatorname{TrG}, \mathrm{BMI}, \mathrm{IS}, \mathrm{LVEF}$ and peak $\dot{V}_{\mathrm{O}_{2}}$ were similar to that of the other patients in CG or TrG. The changes in these variables during intervention (either as control or training patient) did not differ from the respective groups either. It was therefore concluded that the results of this doubly participating group did not interfere with the total study outcome.

Composition of $\operatorname{TrG}$ and CG with respect to gender, race and aetiology of heart failure was similar as were medication use and smoking (Table 1). $\operatorname{Tr} G$ was somewhat younger than $C G$ ( $\operatorname{TrG}, 57 \pm 9$ years; CG, $62 \pm 8$ years).

As expected, male and female patients differed regarding body composition and exercise tolerance, but distribution of data did not cluster separately and therefore 
Table 2 Characteristics and IS in $6 I$ patients with CHF before and after training

Results are expressed as the means \pm S.D. or the geometric mean $\left(95 \%\right.$ confidence interval). $P_{\text {time-effect }}$ and $P_{\text {training-effect }}$, repeated measures ANOVA.

\begin{tabular}{|c|c|c|c|c|c|c|}
\hline & \multicolumn{2}{|l|}{$\operatorname{TrG}(n=36)$} & \multicolumn{2}{|l|}{$\mathrm{CG}(n=25)$} & \multirow[b]{2}{*}{$P_{\text {time-effect }}$} & \multirow[b]{2}{*}{$P_{\text {training-effect }}$} \\
\hline & Baseline & After 6 months & Baseline & After 6 months & & \\
\hline BMI $\left(\mathrm{kg} / \mathrm{m}^{2}\right)$ & $26.9(20.8-39.0)$ & $27.4(21.4-43.9)$ & $26.0(19.9-33.8)$ & $26.3(20.6-33.9)$ & $0.05^{*}$ & 0.61 \\
\hline Body fat $(\%)$ & $36.5 \pm 6.1$ & $36.0 \pm 6.5$ & $34.9 \pm 6.3$ & $35.2 \pm 6.8$ & 0.84 & 0.26 \\
\hline FFM (kg) & $51.5 \pm 9.1$ & $52.3 \pm 10.4$ & $51.3 \pm 6.9$ & $51.6 \pm 7.3$ & 0.13 & 0.43 \\
\hline FM (kg) & $29.9 \pm 8.5$ & $29.9 \pm 9.8$ & $27.9 \pm 7.7$ & $28.5 \pm 8.0$ & 0.73 & 0.26 \\
\hline WC (cm) & $97.9 \pm 12.4$ & $97.3 \pm 13.7$ & $97.9 \pm 10.1$ & $98.1 \pm 9.4$ & 0.88 & 0.48 \\
\hline Fasting glucose level (mmol/l) & $5.4 \pm 0.5$ & $5.5 \pm 0.6$ & $5.5 \pm 0.7$ & $5.3 \pm 0.5$ & 0.23 & 0.15 \\
\hline Fasting insulin level (m-units/l) & II.3 (1.9-49.6) & $12.4(3.4-36.1)$ & $12.5(1.6-28.7)$ & I0.I (I.4-25.6) & 0.26 & 0.12 \\
\hline IS $(\mu \mathrm{g} / \mathrm{kg}$ of $\mathrm{FFM} / \mathrm{min} / \mathrm{m}$-unit $/ \mathrm{l})$ & $27.2(13.9-72.6)$ & $30.7(10.5-70.2)$ & $28.4(13.0-48.7)$ & $30.0(12.0-64.8)$ & $0.76 \dagger$ & $0.52 \dagger$ \\
\hline HOMA index & $2.7(0.5-11.8)$ & $2.9(0.8-10.5)$ & $3.0(0.3-6.2)$ & $2.4(0.3-5.2)$ & 0.41 & 0.20 \\
\hline $\begin{array}{l}\text { * Significant at } P<0.05 \text {. } \\
\dagger \text { Corrected for BMI. }\end{array}$ & & & & & & \\
\hline
\end{tabular}

both groups were analysed as a whole. IS and DPA score were similar.

Compliance to the supervised training program was $88 \pm 1 \%$, and to the home training program $120 \pm 40 \%$. On average, almost half of the patients exercised more than two times per week at home. Overall compliance to the training program was $100 \pm 20 \%$.

\section{Body composition}

BMI of $27 \mathrm{~kg} / \mathrm{m}^{2}$, body fat of $35 \%$ and WC of $98 \mathrm{~cm}$ indicate that these groups were closer to overweight than underweight (Table 2). After intervention, BMI was slightly increased both in $\operatorname{TrG}$ and CG (both $1 \%$ increase; $F=4.160, P<0.05$; Table 2 and see Table 4). In $\operatorname{TrG}$ the increase in $\mathrm{BMI}$ was coupled with a $1.4 \%$ increase in FFM and a $0.4 \%$ decrease in FM. In CG, FFM increased by $0.5 \%$ and FM by $2.0 \%$. These changes were, however, not statistically significant.

\section{IS}

At baseline (in 77 patients), HOMA index was elevated $(3.7 \pm 2.6)$, indicating that IS was impaired. IS measured by clamp was negatively correlated with fasting insulin $(r=-0.43, P<0.01)$, BMI $(r=-0.50, P<0.001)$, WC $(r=-0.54, P<0.001)$ and HOMA index $(r=$ $-0.51, P<0.001)$.

Plasma glucose levels during the third hour of the clamp were comparable at baseline and after intervention $(5.0 \mathrm{mmol} / \mathrm{l}$ and $5.0 \mathrm{mmol} / \mathrm{l}$ respectively), as were plasma insulin levels (365 m-units/1 and $350 \mathrm{~m}$-units/l respectively). These levels were similar in $\operatorname{TrG}$ and CG. After intervention, IS seemed to be higher in both $\operatorname{TrG}$ and CG $(F=3.897$, time effect, $P=0.05)$ (Table 2 and see Table 4).

Since BMI was slightly increased, and BMI was related to IS, the effect of training on IS was tested using BMI as co-variate. The time effect no longer existed, and although the increase in $\operatorname{TrG}$ was almost twice as high as in CG $(20 \%$ and $11 \%$ respectively; Table 2$)$, the effect of training was statistically not significant $(P=0.5)$. Moreover, as can be seen in Table 4, IS increased in all patients in the $\operatorname{TrG}$, whereas in the CG IS decreased in several patients. The presence of patients with IFG did not affect outcome with regard to IS, since results did not change when these patients were excluded from analysis.

\section{Effect of medication on IS}

Since ACE inhibitors, loop diuretics and $\beta$-blockers are known to affect IS [21-23], medication use has to be considered a potential confounder in the measurement of IS and of the effect of training. Unfortunately, it was not possible to analyse subgroups of patients who used only ACE inhibitors, loop diuretics or $\beta$-blockers, since these subgroups were far too small. Therefore, analysis was done in patients who used at least ACE inhibitors, loop diuretics or $\beta$-blockers compared with patients who did not use these kinds of medication. The baseline IS of ACE inhibitor users compared with those who did not use this kind of medication was similar. Comparison of loop-diuretic users or $\beta$-blocker (either selective or non-selective) users with the respective non-user groups showed the same result. None of these three groups of medication affected the change in IS as a result of training or over time.

\section{Determinants of IS}

In a previous paper we described the determinants of IS in CHF patients [7]. BMI, smoking, age and DPA turned out to be the main predictors, whereas LVEF and aetiology of heart failure contributed only moderately to the observed variance [7]. These determinants did not affect the change in IS during intervention. 
Table 3 Exercise tolerance of both groups $(n=6 I)$

Results are expressed as the means \pm S.D. or the geometric mean $\left(95 \%\right.$ confidence interval). $P_{\text {time-effect }}$ and $P_{\text {training-effect, }}$, repeated measures ANOVA.

\begin{tabular}{|c|c|c|c|c|c|c|}
\hline & \multicolumn{2}{|l|}{$\operatorname{TrG}(n=36)$} & \multicolumn{2}{|l|}{ CG $(n=25)$} & \multirow[b]{2}{*}{$P_{\text {time-effect }}$} & \multirow[b]{2}{*}{$P_{\text {training-effect }}$} \\
\hline & Baseline & After 6 months & Baseline & After 6 months & & \\
\hline LVEF $(\%)$ & $28.9 \pm 8.9$ & $28.5 \pm 8.2$ & $26.2 \pm 6.6$ & $28.1 \pm 10.1$ & 0.22 & 0.59 \\
\hline DPA score & $12.5 \pm 8.1$ & $13.2 \pm 7.5$ & $12.4 \pm 8.8$ & $12.8 \pm 7.3$ & 0.42 & 0.76 \\
\hline Peak $\dot{V}_{0_{2}}(\mathrm{ml} / \mathrm{min})$ & $1588 \pm 469$ & $1670 \pm 496$ & $1456 \pm 456$ & $1408 \pm 390$ & 0.56 & $0.03^{*}$ \\
\hline Peak $\dot{V}_{\mathrm{O}_{2}}$ (ml/kg of body mass per $\left.\mathrm{min}\right)$ & $19.6 \pm 4.9$ & $20.3 \pm 5.4$ & $18.3 \pm 4.7$ & $17.5 \pm 4.4$ & 0.85 & 0.08 \\
\hline Peak workload $(\mathrm{W})$ & $105 \pm 35$ & $112 \pm 38$ & $95 \pm 39$ & $91 \pm 35$ & 0.27 & $0.01^{*}$ \\
\hline Peak respiratory quotient (RQ) & $1.11 \pm 0.09$ & $1.13 \pm 0.08$ & $1.08 \pm 0.10$ & $1.08 \pm 0.11$ & 0.33 & 0.15 \\
\hline Peak HR (beats/min) & $146 \pm 22 \uparrow$ & $148 \pm 25$ & $133 \pm 26 \dagger$ & $|3| \pm 29$ & 0.64 & 0.40 \\
\hline
\end{tabular}

Table 4 Changes in relevant variables during intervention in TrG and CG

Results are expressed as the mean ( $95 \%$ confidence interval).

\begin{tabular}{|c|c|c|}
\hline & \multicolumn{2}{|c|}{ Absolute changes during intervention } \\
\hline & $\operatorname{TrG}(n=36)$ & $C G(n=25)$ \\
\hline BMI $\left(\mathrm{kg} / \mathrm{m}^{2}\right)$ & $0.2(-0.2-0.6)$ & $0.2(0.06-0.4)$ \\
\hline FFM (kg) & $0.8(-0.2-1.9)$ & $0.3(-0.6-I . I)$ \\
\hline IS $(\mu \mathrm{g} / \mathrm{kg}$ of $\mathrm{FFM} / \mathrm{min} / \mathrm{m}$-unit $/ \mathrm{l})$ & $4.7(0.4-9.0)$ & $2.7(-1.8-7.1)$ \\
\hline LVEF $(\%)$ & $1.0(-2.7-4.7)$ & $2.6(-2.3-7.5)$ \\
\hline Peak $\dot{V}_{0_{2}}(\mathrm{ml} / \mathrm{min})$ & $81(|-| 6 \mid)$ & $-48(-122-27)$ \\
\hline $\begin{array}{l}\text { Peak } \dot{V}_{0_{2}}(\mathrm{ml} / \mathrm{kg} \text { of body } \\
\text { mass per min) }\end{array}$ & $0.7(-0.6-1.9)$ & $-0.8(-1.7-0.1)$ \\
\hline Peak workload (W) & $8(2-13)$ & $-3(-9-2)$ \\
\hline
\end{tabular}

\section{Exercise tolerance}

\section{DPA}

Most patients predominantly participated in household activities, and 15 patients took part in sports activities, varying from tennis to cardiofitness. The DPA score of 12 (Table 3) was comparable to what was found in healthy elderly Dutch people, who were about 10 years older than patients in the present study [20]. The DPA score did not change in $\operatorname{TrG}$ or CG during intervention.

Peak $\dot{V}_{2}$ and left ventricular function

At baseline, peak $\dot{V}_{\mathrm{O}_{2}}(\mathrm{ml} / \mathrm{kg}$ per $\mathrm{min})$ was $66 \pm 17 \%$ of predicted peak $\dot{V}_{\mathrm{O}_{2}}$ based on height, weight, gender and age [24]. Training resulted in a significant increase in peak $\dot{V}_{\mathrm{O}_{2}}(6 \%$ increase in $\operatorname{TrG}$ as opposed to $2 \%$ decrease in CG, $F=5.259, P<0.05$ ) (Tables 3 and 4 ). LVEF did not change during intervention (Table 3 ).

\section{Relationship between peak $\dot{V}_{\mathrm{O}_{2}}$ and IS}

At baseline, no significant correlation was found between IS and peak $\dot{V}_{\mathrm{O}_{2}}$. In both groups ( $\operatorname{TrG}$ and $\mathrm{CG}$ ) the changes in IS and peak $\dot{V}_{\mathrm{O}_{2}}$ during intervention were calculated and correlated positively $(r=0.30, P<0.05)$.

\section{DISCUSSION}

In the present study we determined the effect of a 6month training program on IS and described how this related to peak $\dot{V}_{\mathrm{O}_{2}}$ in $\mathrm{CHF}$.

As expected, peak $\dot{V}_{\mathrm{O}_{2}}$ increased as a result of the training program. Training did not result in a statistically significant increase in IS, although the increase in the $\operatorname{TrG}$ was almost twice as high as in the CG. The change in peak $\dot{V}_{\mathrm{O}_{2}}$ in both groups ( $\operatorname{TrG}$ and CG combined) was related to the change in IS during intervention.

\section{Drop-out rate}

The drop-out rate of $26 \%$ did not differ from other studies that applied a training period of 6 months $[10,25]$. Since no differences in measured variables were found between patients that completed the study and patients that dropped out, the final group of 61 patients can be considered representative for the originally selected study population.

\section{IS}

CHF patients in the present study presented with IS which was lower than IS of obese subjects, but higher than IS of Type II diabetic patients [26] and comparable to IS in another group of CHF patients [5]. As expected, IS correlated negatively with fasting plasma insulin, age, HOMA index and BMI (as a measure of obesity which is known to be strongly associated with IS). These correlations underscore the validity of the clamp technique used in the present study.

IS increased over time in both groups and this increase was related to a small, but statistically significant, increase in BMI. This is remarkable, since BMI and IS were inversely related. The increase in BMI in $\operatorname{TrG}$ was the result of an increase in FFM, whereas in CG both FFM and FM increased. However, these changes were statistically not significant and we can only speculate that the positive effect of FFM on IS seems to be stronger than the negative effect of FM. 
The present study is the first randomized controlled study into the effect of training on IS and the relationship with peak $\dot{V}_{\mathrm{O}_{2}}$ in CHF patients. Although IS increased to a greater extent in the $\operatorname{TrG}$ than in the CG, this difference did not reach statistical significance. Based on results in healthy subjects and diabetic patients, an increase was expected [8]. An explanation for the discrepancy might be that the patient group was not of a sufficient size to reveal an effect of training on IS. Post-hoc power analysis resulted in a power of 0.1 , which is rather low. However, as the explained variance was far below $10 \%$, a significant result with a higher number of patients may introduce a type I error. Moreover, such a low explained variance makes substantial clinical relevance unlikely. Had the training program lasted longer, the differences between the groups might have been more pronounced. In addition, the training program may not have been sufficiently specific for improving IS. We will elaborate on that in the next section.

Our results seem to be in contrast to the study of Pietilä et al. [5]. That work was a placebo-controlled study into the combined effects of Celiprolol (vasodilating $\beta_{1}$-selective adrenoreceptor antagonist that is known to increase IS) and physical training on IS in CHF. Only the combination of physical training and use of Celiprolol resulted in a statistically significant increase in IS, indicating that Celiprolol enhanced the effect of training. Since that study lacked a non-training control group, it is not clear whether the increase in IS was indeed due to training. In the present study, training did not improve IS significantly, not even in patients who used (selective) $\beta$-blockers.

In another study into the effect of training on IS in $\mathrm{CHF}$ patients, training resulted in a $25 \%$ increase in IS and a $20 \%$ increase in peak $\dot{V}_{\mathrm{O}_{2}}$ [3]. In the non-training control group no changes were observed. The study differed from ours with respect to age, aetiology of heart failure and severity of disease; all subjects were men and currently not smoking. We previously reported these parameters as determinants of IS in CHF [7]. When we corrected our results for these parameters, still no effect of training on IS was found. In addition, the previous study [3] was hampered by a very small number of patients and a non-randomized design. The results may therefore not be decisive.

This leads to the tentative conclusion that in subjects with CHF, in contrast with healthy subjects and patients with Type II diabetes, IS is not necessarily affected by physical training.

\section{Exercise tolerance}

\section{DPA}

The DPA score did not include activities related to the training program, and did not change during intervention in either group. This indicates that no decrease in other
DPAs occurred in $\operatorname{TrG}$ to compensate for the extra training activities. Therefore the training program did not interfere with usual daily life activities.

\section{Peak $\dot{V}_{2}$}

Training resulted in an increase in peak $\dot{V}_{\mathrm{O}_{2}}$ in $\operatorname{TrG}$, whereas peak $\dot{V}_{\mathrm{O}_{2}}$ decreased by $2 \%$ in CG. This indicates that the natural course of decline in exercise tolerance has been prevented in the $\operatorname{TrG}$ and that there is even a small improvement. The increase in peak $\dot{V}_{\mathrm{O}_{2}}$ is comparable with the increase observed in a study in which combination of strength and endurance training was also applied [25]. Other studies reported larger increases in peak $\dot{V}_{\mathrm{O}_{2}}$ (30 and $20 \%$ ) [9,10], but those studies applied endurance training and evaluation of the training program was training specific. Our study showed that even if exercise tolerance was measured non-specifically, an increase in exercise tolerance could still be obtained.

\section{Training program}

The results of our study showed that a combination of home-based and supervised strength and endurance training, without complex training equipment, was safe, feasible and equally effective, with respect to improving exercise tolerance, as training using advanced equipment for $\mathrm{CHF}$ patients.

\section{Relationship between IS and peak $\dot{V}_{\mathbf{O}_{2}}$}

The increase in peak $\dot{V}_{\mathrm{O}_{2}}$, was not accompanied by an increase in IS. An explanation might be found in muscle fibre type distribution. Since training in the present study comprised both endurance and strength exercises, we might speculate that particularly type IIa fibres have been affected by training. Type IIa fibres are known to have metabolic characteristics that are intermediate between those of type I (high oxidative, low glycolytic capacity and high capillary density) and type IIb (low oxidative, high glycolytic capacity and low capillary density) fibres [27]. There are strong indications that IS of type IIa fibres is also intermediate between that of type I (high IS) and IIb (low IS) fibres [28]. This would explain why peak $\dot{V}_{\mathrm{O}_{2}}$ did increase after training, whereas IS did not.

In spite of this lack of concomitant increase due to training, the change in IS in the total group of patients was positively related to the change in peak $\dot{V}_{\mathrm{O}_{2}}$. Little is known about the mechanism by which IS relates to $\mathrm{CHF}$ and attention is focused on vascular effects of insulin being impaired across a number of insulinresistant states [4]. Since metabolic and vascular effects of insulin share common intracellular signalling pathways [29], IS measured by clamp (as in the present study) is presumably representative of both metabolic and vascular effects of insulin. It seems plausible to suggest that any increase in IS represents an improvement in vascular effects of insulin which is, in part, responsible for the increased exercise tolerance. 
Studies on training in large groups of CHF patients, in which both metabolic and vascular effects of insulin before and after the clamp, as well as before and after exercise testing, are assessed, will shed more light on the action of insulin (either metabolic or vascular) for the improvement of exercise tolerance in $\mathrm{CHF}$.

\section{Conclusion}

CHF patients can safely participate in a training program that consists of strength and endurance exercises, and participation will not lead to a decrease in activities in daily life. Our training program prevented deterioration of peak $\dot{V}_{\mathrm{O}_{2}}$ and resulted in a modest increase in peak $\dot{V} \mathrm{O}_{2}$.

CHF patients in our study were markedly insulin resistant and thereby at risk of the development of diabetes mellitus. Whether physical training is of use in decreasing this risk, i.e. by increasing IS, cannot be concluded yet.

\section{ACKNOWLEDGMENTS}

We thank Professor Dr H. Folgering for methodological advice and Dr E. Bol for statistical advice. This study was funded by: Netherlands Heart Foundation (grant 98.125), Sorbo Heart Foundation, Foundation for Research on Cardiovascular Disease and Meander Foundation for Scientific Research (Amersfoort, The Netherlands).

\section{REFERENCES}

1 Drexler, H., Riede, U., Münzler, T., König, H., Funke E. and Just, H. (1992) Alterations of skeletal muscle in chronic heart failure. Circulation 85, 1751-1759

2 Swan, J. W., Walton, C., Godsland, I. F., Clark, A. L., Coats, A. J. S. and Oliver, M. F. (1994) Insulin resistance in chronic heart failure. Eur. Heart J. 15, 1528-1532

3 Kemppainen, J., Tsuchida, H., Stolen, K. et al. (2003) Insulin signalling and resistance in patients with chronic heart failure. J. Physiol. (Cambridge, U.K.) 550, 305-315

4 Baron, A. D. (1994) Hemodynamic actions of insulin. Am. J. Physiol. 267, E187-E202

5 Pietilä, M., Malminiemi, K., Huupponen, R. et al. (2000) Celiprolol augments the effect of physical exercise on insulin sensitivity and serum lipid levels in chronic heart failure. Eur. J. Heart Fail. 2, 81-90

6 Swan, J. W., Anker, S. D., Walton, C. et al. (1997) Insulin resistance in chronic heart failure: relation to severity and etiology of heart failure. J. Am. Coll. Cardiol. 30, 527-532

7 Sabelis, L. W. E., Senden, P. J., Zonderland, M. L. et al. (2003) Determinants of insulin sensitivity in chronic heart failure. Eur. J. Heart Fail. 5, 759-765

8 Koivisto, V. A., Yki-Järvinen, H. and DeFronzo, R. A. (1986) Physical training and insulin sensitivity. Diabetes Metab. Rev. 1, 445-481

9 Hambrecht, R., Niebauer, J., Fiehn, E. et al. (1995) Physical training in patients with stable chronic heart failure: effects on cardiorespiratory fitness and ultrastructural abnormalities of leg muscles. J. Am. Coll. Cardiol. 25, 1239-1249
10 Sullivan, M. J., Higginbotham, M. B. and Cobb, F. R. (1988) Exercise training in patients with severe left ventricular dysfunction. Circulation 78, 506-515

11 Hambrecht, R., Fiehn, E., Weigl, C. et al. (1998) Regular physical exercise corrects endothelial dysfunction and improves exercise capacity in patients with chronic heart failure. Circulation 98, 2709-2715

12 Expert Committee on the Diagnosis and Classification of Diabetes Mellitus (2003) Report of the expert committee on the diagnosis and classification of diabetes mellitus. Diabetes Care 26, S5-S20

13 Hobbs, F. D. R., Jones, M. I., Allan, T. F., Wilson, S. and Tobias, R. (2000) European survey of primary care physician perceptions on heart failure diagnosis and management (Euro-HF). Eur. Heart J. 21, 1877-1887

14 Royal Canadian Air Force (1988) 5BX Plan for Physical Fitness for Men. Penguin Books Ltd, London

15 Meyer, K., Samek, L., Schwaibold, M. et al. (1996) Physical responses to different modes of interval exercise in patients with chronic heart failure - application to exercise training. Eur. Heart J. 17, 1040-1047

16 Schiller, N. B., Acquatella, H., Ports, T. A. et al. (1979) Left ventricular volume from paired biplane two-dimensional echocardiography. Circulation 60,547-555

17 Durnin, J. V. G. A. and Womersley, L. (1974) Body fat assessed from total body density and its estimation from skinfold thickness: measurements on 481 men and women aged from 16 to 72 years. Br. J. Nutr. 32, 77-97

18 DeFronzo, R. A., Tobin, J. D. and Andres, R. (1979) Glucose clamp technique: a method for quantifying insulin secretion and resistance. Am. J. Physiol. 237, E214-E223

19 Matthews, D. R., Hosker, J. P., Rydenski, A. S., Naylor, B. A., Treacher, D. F. and Turner, R. C. (1985) Homeostasis model assessment: insulin resistance and $\beta$-cell function from fasting plasma glucose and insulin concentrations in man. Diabetologia 28, 412-419

20 Voorrips, L. E., Ravelli, A. C. J., Dongelmans, P. C. A., Deurenberg, P. and van Staveren, W. A. (1991) A physical activity questionnaire for the elderly. Med. Sci. Sports Exercise 23, 974-979

21 Bernobich, E., de Angelis, L., Lerin, C. and Bellini, G. (2002) The role of the angiotensin system in cardiac glucose homeostasis: therapeutic implications. Drugs 62, 1295-1314

22 Jacob, S., Rett, K. and Henriksen, E. (1998)

Antihypertensive therapy and insulin sensitivity: do we have to redefine the role of beta-blocking agents? Am. J. Hypertens. 11, 1258-1265

23 Lind, L., Pollare, T., Berne, C. and Lithell, H. (1994) Long-term metabolic effects of antihypertensive drugs. Am. Heart J. 128, 1177-1183

24 Jones, N. L. (1988) Clinical Exercise Testing, p. 305, WB Saunders Company, Philadelphia

25 Delagardelle, C., Feiereisen, P., Krecké, R., Essamri, B. and Beissel, J. (1999) Objective effects of a 6 months' endurance and strength training program in outpatients with congestive heart failure. Med. Sci. Sports Exercise 31, 1102-1107

26 Segal, K. R., Edano, A., Abalos, A. et al. (1991) Effect of exercise training on insulin sensitivity and glucose metabolism in lean, obese and diabetic men. J. Appl. Physiol. 71, 2402-2411

27 Saltin, B., Henriksson, J., Nygaard, E., Andersen, P. and Jansson, E. (1977) Fiber types and metabolic potentials of skeletal muscles in sedentary men and endurance runners. Ann. N.Y. Acad. Sci. 301, 3-29

28 Ivy, J. L. (1997) Role of exercise training in the prevention and treatment of insulin resistance and non-insulindependent diabetes mellitus. Sports Med. 24, 321-336

29 Zeng, G. and Quon, M. J. (1996) Insulin-stimulated production of nitric oxide is inhibited by wortmannin. Direct measurement in vascular endothelial cells. J. Clin. Invest. 98, 894-898 